\title{
A FRONTEIRA NA POESIA DE FABIÁN SEVERO
}

\section{JULIANA SILVA CARDOSO MARCELINO SILVINA LILIANA CARRIZO}

RESUM 0: O presente artigo objetiva apresentar a prática poética de Fabián Severo, que tem como inspiração Artigas, cidade fronteiriça (Brasil - Uruguai). O poeta penetra num universo pluridimensional e permite analisar a lógica perversa da homogeneização cultural, instaurada pelo sistema linguístico mundial e de circulação de informação. No decorrer do fluxo poético, observam-se recortes, reminiscências do cotidiano, interstícios, ressonâncias, deslocamentos e apegos dentro de uma dinâmica que enleia do real à ficção o sujeito fronteiriço. Severo realiza, através do portunhol, a desconstrução do capital linguístico-literário do Português e do Espanhol. Essa variedade linguística colaborou para questionar o imaginário do Uruguai como um país monolíngue e possibilitou uma maior compreensão do que seja a fronteira.

PALAVRAS-chave: Poesia; Fabián Severo; América Latina; sujeito fronteiriço; tempo.

\section{INTRODUÇÃO}

O poeta uruguaio Fabián Severo nasceu em Artigas (Uruguai), cidade que faz fronteira com Quaraí (Brasil). Publicou seu livro de poemas, intitulado Noite nu Norte, no ano de 2010, em portunhol. Em 2011, republicou-o em versão bilíngue - Portunhol e Espanhol -, sob o título Noite nu Norte/ Noche en el norte - poesía de la frontera, constituído por 58 poemas intitulados por números. O compilado se dispõe em ordem crescente (de uno ao sincuentioito).

Severo busca na obra citada ilustrar, através de sua experiência de vida, a realidade fronteiriça por meio da construção de memórias individuais e coletivas, sem se comprometer com a verdade. Todavia, ressalta-se que memória também 
é ficção. Sua poética é ungida por combinações de palavras, sons, ritmos e musicalidade, em que utiliza a língua afetiva, o portunhol, ao invés da língua oficial, o espanhol, possibilitando enxergar a fronteira em sua indefinição, atravessada por conflitos. São percebidas as implicações que cabem a essa fronteira, seja no âmbito literário, social, político, linguístico, histórico ou geográfico.

Ao ler os poemas do autor, o leitor é envolvido por uma fronteira na qual não existe uma linha de demarcação entre Brasil e Uruguai. Artigas será sempre uma região que agrega o mesmo céu e a mesma terra em sua formação, compondo um cenário repleto de histórias e traços culturais advindos da mescla entre duas nações. No poema "Oito", é possível compreender essa fusão: "Archigas fala i baila com aqueles/ mas trabaja i come com estos” (SEVERO, 2011, p. 26).

Para que se possa conhecer a fronteira em Artigas, cidade de origem de Fabián Severo, faz-se necessário imergir no processo de desenvolvimento da América Latina, abdicar do tempo historicizado fundamentado no atraso e na anterioridade e em demarcações temporais que se organizam sequencialmente em colonialismo e pós-colonialismo. Tais delimitações são de cunho ilustrativo, visto que não houve o rompimento entre elas. Traços do colonialismo estão presentes culturalmente nas nações independentes. Desconstruir a ideia de tempo histórico como ponto de partida para se deslindar a realidade de uma nação é imprescindível.

Através da gênesis marcada pela consolidação das nações "periféricas" e os mecanismos estratégicos de dominação impostos pela Europa, numa tentativa de homogeneizar as nações dominadas e ocultar as diferenças e conflitos existentes para a obtenção do poder, pode-se observar o universo fronteiriço agastado em fragmentos, ruídos e silêncios. Ao pensar em modernidade, logo podemos concluir que o modelo civilizatório seguido pelas nações periféricas foi o europeu, não por escolha, mas por exigência do dominador numa perspectiva dualista de nação: atrasada $X$ civilizada.

Fabián Severo, por meio de sua prática artística, nos ensina a resistir diante do apagamento de vidas silenciadas pelo sistema neoliberal que assola as nações das "bordas". Ao escrever as histórias da fronteira em portunhol, uma língua flutuante, sem um esquema ortográfico ou regras gramaticais, que variam de fronteira para fronteira, bairro, faixa etária, falada pelos pobres, originada das perdas 
e carências na fronteira, o poeta proporciona ao tempo uma abertura para o "estranho", já que o portunhol é resultado do acolhimento de duas línguas permeado por todas as suas implicações. Por estar "fora” e, ao mesmo tempo, ser parte do "todo", o portunhol promove uma temporalidade na fronteira não estagnada em um passado aferrado ao imaginário de nação. O poema "Sincuentioito" (SEVERO, 2011, p. 91), de Noite nu Norte, emana o sentimento do sujeito "fronteirizo" e evidencia a fronteira Artigas como uma região composta por ruídos e silêncios:

Sincuentioito

Nos semo da frontera

Como u sol que nase alí tras us ucalito

Alumeia todo u día ensima du río

I vai durmí la despós da casa dua Rodrigues.

Da frontera como a lua

Quis faz a noite cuasi día

Deitando luar nas maryen del Cuareim.

Como el viento

Que ase bailar las bandera

Como a yuva

Leva us ranyo deles yunto com los nuestro.

Todos semo da frontera

Como esses pássaro avuando de la pra qui

Cantando um idioma que todos intende.

Viemos da frontera

Vamo pra frontera

Como us avó i nossos filio

Comendo el pan que u diabo amasó

Sofrendo neste fin de mundo.

Nos semo a frontera 


\section{Mas que cualquérío}

Mas que cualqué puente.

\section{(SEVERO, 2011, p. 91)}

A globalização neoliberal dissemina a ideia de "igualdade potencial e a uniformidade de todas as pessoas e culturas" (LANDER, 2005, p. 59), porém, continua a explorar as riquezas naturais das nações "das bordas” e a mão de obra, promovendo a destruição da integridade humana em favor do capitalismo. Ao colocar o mercado literário em pauta, não há como não correlaciona-lo com o sistema neoliberal que pulveriza todas as instâncias pertencentes ao corpo social. Noite nu Norte expõe em sua prática escrita a dificuldade em transpor os limites da língua dominante (espanhol) e, com ela, toda sua herança, capital literário e imaginário.

A obra em estudo mostra-se distante do padrão estético universal, no qual títulos consagrados e reconhecidos literariamente servem como instrumentos legisladores do reconhecimento literário. Nesse sentido, Severo possui como matéria prima a fronteira Artigas, uma região sem notoriedade, e escreve em uma língua sem prestígio, o que rompe com a tradição que refina a literatura, sem deixar de mencionar as políticas públicas uruguaias que buscam a hegemonia da nação escamoteando o cenário pluricultural e complexo da fronteira.

\section{O PROCESSO DE COLONIZAÇÃO DA AMÉRICA LATINA}

A colonização da América Latina ainda perdura na atualidade, reconfigurada em um sistema “moderno - colonial” (LANDER, 2005, p. 4). Visualiza-se um mecanismo interno social e cultural que insiste em delinear identidades nacionais, abrangendo uma perspectiva histórico-cultural do continente e negando a fragmentação e a complexidade da formação de povos sujeitos à exclusão e à aceitação forçada das convicções coloniais e nacionais que definem uma civilização e a estereotipa em versões retardatárias. São países submetidos à expropriação de suas essências identitárias e progressistas, nações onde o poder soberano regula e educa os territórios subalternizados. 
A América Latina, durante todo o seguimento de fortalecimento do sistema capitalista, respaldado na política neoliberal, isocronicamente constituído por estratégias colonizadoras e de cunho imperialista de dominação, passou a sofrer, de acordo com sociólogo venezuelano Edgardo Lander (2005, p. 10), de um "conformismo colonial”. Isso por efeito da atuação dos conquistadores ibéricos que ordenaram, por volta dos séculos XVIII e XIX, a América em várias instâncias com imposições linguísticas, inserção de conhecimentos, contribuindo para a construção de uma memória coletiva seletiva e para a criação de um imaginário de nação. Esse cenário resultou na formação totalizadora de pensar o espaço e o tempo, respaldada na experiência europeia.

Vale mencionar, nesse contexto, o filósofo Michel Foucault (2004), que aborda as relações de poder dentro da estrutura social e a naturalização das conexões do sistema capitalista-liberal e das microesferas sociais, tendo como origem a influência da supremacia europeia. Consequentemente, essa ideia ocasiona a submissão dos colonizados, marcados pela expropriação de terras, silenciamentos de povos julgados inferiores, como os indígenas e os negros, e a exploração das riquezas naturais e do trabalho, resultando em um "regime de normatização" (LANDER, 2005, p. 12) e culminando na formação do sujeito-latino-americano contaminado pelo poder hegemônico europeu.

O desenvolvimento identitário dos países colonizadores, conhecidos, ainda segundo Lander, como países do "centro”, através de sua produção de conhecimentos, busca instaurar na sociedade sua supremacia, utilizando de artifícios segregacionistas, seja no âmbito racial, cultural ou linguístico para que se perpetue a legitimidade e a consolidação dessas nações dominadoras. Ao persistir na manutenção de uma língua "pura”, as nações hegemônicas constroem um paradigma de identidade nacional, vinculado a uma dominância política, econômica e cultural.

Os historiadores tradicionais acreditam ser possível delinear a "gênesis" das nações dentro de uma perspectiva cronológica cultural, conforme o historiador Benedict Anderson (2008), sustentada pelas políticas coletivas e marcada pelas nacionalidades oficializadas pelos registros históricos, poucas lembranças e muitos esquecimentos. Ao transpassar pelo contexto histórico-cultural da América 
Latina, constata-se a participação das concepções universais respaldadas na Europa que interferem nos direitos dos indivíduos e pensamentos, realizando na temporalidade um imaginário do que seria a nação.

Anderson (2008) propõe uma reflexão sobre a nação limitada e a construção de fronteiras fixas, em que as comunidades são submetidas a imitar a nação soberana, inventando uma unidade identitária que se exterioriza como homogênea e solidificada e, simultaneamente, mascara as hierarquias e desigualdades em um tempo linear e vazio, permeado por um caráter excludente. Ao questionar a escassez na temporalidade, reconhecendo a nação dentro de uma limitação estabilizada e imaginada que resulta por engessar a realidade, permite-se vislumbrar a possibilidade de descentrar, modificar e recuperar tempos através da literatura, direcionando o ponto de discussão deste artigo.

\section{ARTIGAS, UMA FENDA NO TEMPO}

Artigas, cidade localizada na região Norte do Uruguai, é constituída por uma população rural desfavorecida economicamente. Faz divisa com o município brasileiro de Quaraí, sendo notável a inter-relação entre os vizinhos, circundada pela aproximação social, cultural e econômica. É conhecida como "zona seca”, onde não há impedimentos para que se obtenha o contato entre as nações. Artigas interliga os países pela ponte Internacional da Concórdia sem que haja interferências no quesito de segurança para refrear a permissão de trânsito entre as cidades. O poema "Vintiún" apresenta essa realidade de "zona seca":

\section{Vintiún}

\section{Serto día que yo istava triste}

Purque me tiñan quitado tudo

Lo que trasía de Brasil.

Mi tío, ques soldado i viayó por todo u mundo

\section{Me dise}

Noum te queya

Porque tein lugar aonde ni te deiyan entrá.

Yo ayo que ele disse isso porque yo soy burro

I no termine la escuela. 
Purque se Deus isiste i semo todos ijo del

Como vai avé lugar aonde no te deiyen entrá

(SEVERO, 2011, p. 39)

Essa região fronteiriça é um exemplo de resistência ao apagamento de histórias que o tempo linear insiste em dissimular. Ludmer (2013) atenta para a problemática temporal permeada por tensões: "O tempo é um problema cultural pela quantidade de passado, de memória e de história que existe no presente. E, finalmente, um problema político com questões sobre leis e decretos de necessidade e urgência" (LUDMER, 2013, p. 21). Severo, em sua poética, ilustra essa região esquecida, "o limbo fronteiriço", imaginado em um tempo suspenso entre passado e presente, entre o que é real ou ficção. Todavia, revela-se uma essência extremamente genuína do recordar para se construir memórias imbuídas pela experiência fronteiriça, como se pode observar no poema "Treis", a seguir:

Treis

Noum sei como será nas terra sivilisada

Mas ein Artigas

Viven los que tienen apeyido.

Los Se Ninguéim

Como eu

Semo da frontera

Neim daqui neim dalí

No es nosso u suelo que pisamo

Neim a língua que falemo

(SEVERO, 2011, p. 21)

A obtenção dessas informações a respeito da história do Uruguai, em específico da cidade fronteiriça de Artigas, é de suma importância para que se localize, na ambivalência do tempo, a prática poética de Fabián Severo, em Noite nu Norte/ Noche en el norte. 
Na obra supracitada, o sujeito poético reinventa o presente, admitindo tempos de possibilidades nas quais se concatenam o passado a eixos distintos. Recuperam-se imagens de outras esferas ao longo da vivência experienciada no afeto, em crenças, silêncios e, simultaneamente, ressignificam-se sentidos dentro da temporalidade, recusando cronometrar o tempo da história e afirmando o movimento pendular do tempo que se rui no vai e vem, passado-presente. O sujeito poético busca, através da memória, uma mudança no tempo que se transforma por meio do preenchimento da fenda temporal, acrescentando, além dos elementos suscetíveis ao poder direcionados às políticas nacionais, territoriais, linguísticas e de caráter imperialista. A dinâmica interna do subalterno, no poema intitulado "Dois”, elucida essa ideia de fenda temporal inundada de ruídos, indo contra um tempo marcado pelo silêncio: "Artigas e uma estasión abandonada/ A esperença ditrás de um trein que no regresa/ uma ruta que se perde rumbo ao sur" (SEVERO, 2011, p. 20).

A crítica teórica Gayatri Spivak (2010) elucida a dificuldade do subalterno em se apresentar dentro do discurso, sem que haja a interferência do discurso hegemônico, inclusive, em razão da não escuta e por estar do lado de fora da história. A partir desse cenário, Fabián Severo se depara com o desafio de traçar um caminho no qual a subalternidade possa se pronunciar e, simultaneamente, abalar "os limites representacionais, bem como seu próprio lugar de enunciação e sua cumplicidade no trabalho intelectual" (SPIVAK, 2010, p. 18). Em "Sincuentiséis”, transcrito a seguir, o sujeito poético externaliza a necessidade de se fazer presente na composição social e insiste mesmo diante do silenciamento:

\section{Sincuentiséis}

Cuando uno es pobre

i eu so pobre,

no se puede isquesé de aonde viene.

\section{Asvés yo voi na carniceira}

veo el Luisito trabaliando, el me atende

i yo quero le desir

tu te lembra Luisito

cuando nos iva nel río casá vieja del agua 


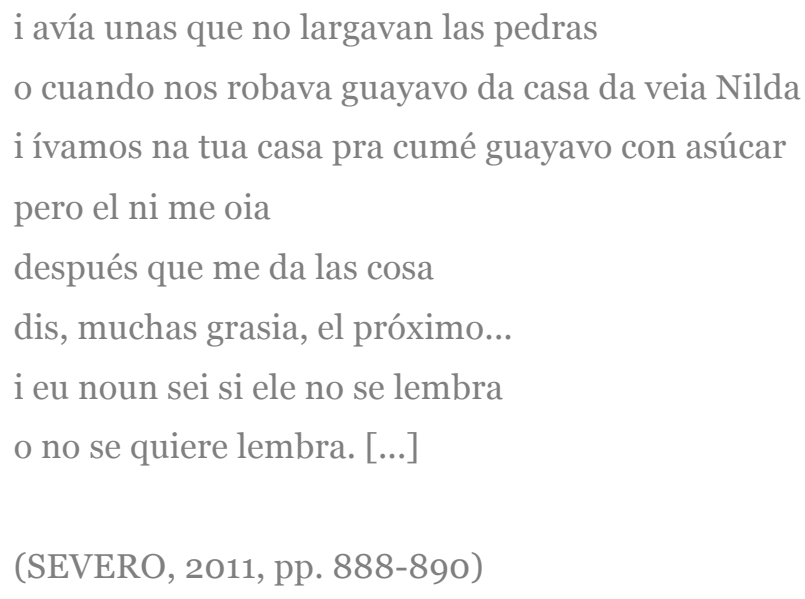

Ao apresentar o sujeito deslocado do imaginário nacional, assinalado pela desigualdade social e com propósitos históricos distintos, constata-se que o subalterno também manifesta, segundo Bhabha (2011), uma "autoridade social". É pertinente traçar o conceito de nação, considerando a história individual repleta de experiências como uma ferramenta fundamental para a compreensão da história do coletivo, adicionando à construção da memória um desdobramento que se reconfigura a partir da ótica do minoritário, no cenário cultural literário. Vejamos nos trechos do poema "Dose", de Noite nu Norte/ Noche en el norte:

\section{Dose}

Artigas tevi um seu yeio distrela

Um río yeio de peiye

Um campo verde, asím de árbol

Uma terra briliante de pedra

Mas alguém levou tudo pra otru povo

I nos fiquemo seim nada

(SEVERO, 2011, p. 30)

O portunhol falado em Artigas, apesar de legitimado por linguistas uruguaios com a "Ley de Educación General", de 2008, e reconhecido como necessário devido à realidade da fronteira bilíngue e diglóssica, ainda está associado à questão socioeconômica desfavorecida e ao grau baixo de escolaridade. É conhe- 
cida como a "língua dos pobres”. Os falantes dessa língua híbrida sofrem preconceito linguístico, sendo, inclusive, vergonhoso praticá-lo em locais públicos. Todavia, é utilizado em situações íntimas como forma de preservar a alteridade.

Fabián, em sua prática poética, resiste dentro do discurso hegemônico. $\mathrm{O}$ poeta busca forças em sua língua de afeto, o portunhol falado em ambiente familiar, e adiciona à linguagem uma performance repleta de musicalidade e plasticidade. No poema "Cuartose”, percebe-se essa mescla cultural (Brasil e Uruguai), o que contribui para a formação do portunhol como uma língua híbrida e representativa para os sujeitos subalternizados pertencentes a Artigas, uma vez que esses sujeitos se pensam, se imaginam e se recriam imersos nesse limbo.

\section{Cuartose}

\section{Desde piqueno}

vemo seus programa

iscutemo suas música

aprendemo sus baile

cumemo sua comida

resemo seus santo

\section{(SEVERO, 2011, p. 32)}

Em Artigas, a utilização das línguas (português e espanhol) se dá devido a circunstâncias distintas. O português é usado como língua de comércio e o espanhol, de prestígio. Bhabha (2011, p. 230) declara que: "precisamos de um outro tempo de escrita que seja capaz de inscrever as interseções ambivalentes e quiasmáticas de tempo e lugar que constituem a problemática experiência moderna de nação". Através do poema "Tresi", o sujeito poético remete à fronteira como uma outra dimensão que necessita de um outro tempo para que se possa compreender que sempre será uma fenda temporal, uma indefinição diante dos fatos que circunscrevem a história. Vejamos nos versos transcritos: "Antes/ Eu queria ser uruguayo./ Agora/ Quiero ser daqui” (SEVERO, 2011, p. 31).

A poética de Fabián discorda que a história seja criada a partir de um só tempo e ultrapassa o senso comum, compreendendo a fronteira como um lugar pluricultural e crivado de particularidades, no qual a visão horizontalizada do 
tempo linear insiste em esconder e eliminar outras versões repletas de esquecimentos, abandonos e violência. É o que se percebe nos trechos do poema "Trinticuatro":

\section{Trinticuatro}

Mi madre falava mui bien, yo intendía.

Fabi andá fazer los deber, yo fasía.

Fabi traseme meio litro de leite,yo trasía.

Desí pra doña Cora que amañá le pago, yo disía.

Deya isso gurí i yo deiyava.

Mas mi maestra no intendía. Mandava cartas

Mandava cartas en mi caderno.

Todo com rojo (igualsito su cara) i assinava imbaiyo.

Mas mi madre no intendía.

Le isso mim ijo i yo leia.

$[\ldots]$

Intonses serto día mi madre intendío i disde:

Meu fío, tu terás que deiyá la iscuela

I yo deiyé

(SEVERO, 2011, p. 58)

\section{A POÉTICA DO ENTRE LUGAR}

A crítica cultural pós-estruturalista está assumindo um papel de grande relevância na ressignificação dos discursos que remontam a realidade social. Permeado de conflitos, devido à consolidação do cânone que se alicerça a partir da visão hegemônica dos países do centro, com a polissemia de vozes que compõem o cenário pluricultural e através dos deslocamentos e das singularidades, o conceito de cultura está distante de abranger toda a complexidade que o reporta. As culturas das minorias estão alterando a compreensão de espaço que se visualiza através das diferenças. Bhabha (2011), em um entendimento teórico abrangente da cultura, que se respalda na disparidade, menciona a pertinência do indivíduo 
em enxergar os territórios e suas diversidades: "nos habilitará a perceber a articulação da fronteira, do espaço sem raízes e do tempo das culturas" (BHABHA, 2011, p. 83).

Enquanto as nações hegemônicas buscam produzir um discurso totalizante, o enunciado híbrido, em contrapartida, propõe uma conversação a respeito do poder que se manifesta desigual, mas podendo, dentro de uma negociação, ser discutido. A negociação não necessita ser um processo de assimilação, pois a intenção é dialogar sem pretensões de se colocar como um enunciado carregado de supremacia cultural. Ao pensar na fronteira, Artigas remete à ideia de mescla de culturas, e a constatação de interação, ratifica a inviabilidade de se obter uma cultura totalizante, na qual se evidencia a fronteira como um "entrelugar das culturas, ao mesmo tempo desconcertante, semelhante e diverso" (BHABHA, 2011, p. 82).

A obra Noite nu Norte/ Noche en el norte expõe a fronteira e a circunstância de existir entre duas histórias entrecruzadas, ora sutilmente, ora artística e diretamente espontânea. O livro se constrói sobre o desdobramento da fronteira em física, psicológica e afetiva. A aparição de um idioma híbrido, o portunhol, será inconstante e de alto teor plástico e surge de forma inovadora dentro do campo literário que reconhece como língua de prestígio o espanhol. No poema "Vintitrés", o sujeito poético resgata por meio da memória esse amalgamento cultural ao trazer a apresentadora brasileira Xuxa para sua história de infância. Em portunhol é tecida sua poesia:

\section{Vintitrés}

\section{Meu pai arrumava u mate}

levava uma sía pru cantiño da casa de Josefa

i ficava alí pra podé iscutá u informativo.

Nos nou tiña tele.

Uma volta, meus pai fueron comprá uma tele usada.

Fórum de ónibus, eu fiquei isperando.

Cuando yegarum

arrumaron tudo mas a tele nou prendeu.

Tentarum aqui i alí, mas nada. 


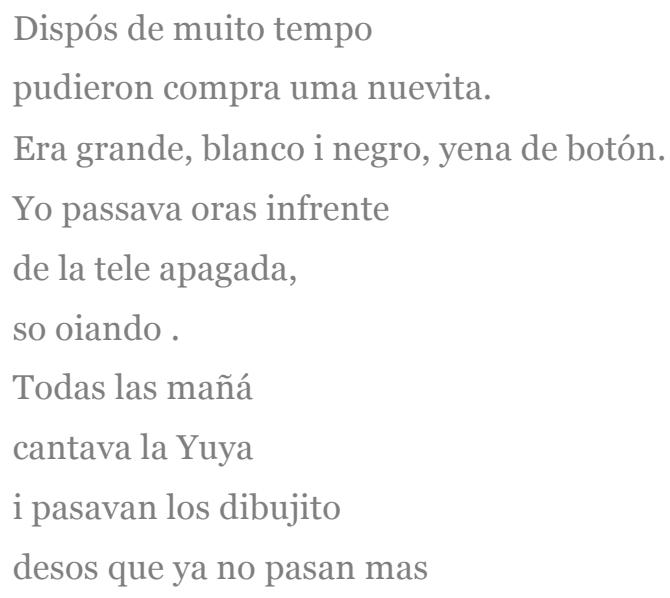

Sonia Torres (1996), respaldada no hibridismo de Bhabha, contribui com uma reflexão sobre a prática do portunhol como uma luta simbólica contra convenções estabelecidas pelo capital literário de uma língua maior, oficial, suas tradições e imaginários. Segundo a autora: "O hibridismo aparece como estratégia, ao invés de simples apropriação ou adoção de uma estética; ele assume um movimento que busca modificar conceitos da nação como organismo coeso e fechado" (TORRES, 1996, p.183).

Diante da fronteira, o sujeito poético transita entre lugares e utiliza uma "entrelíngua", o portunhol, como se retrata no poema "Nove": "Artigas teim uma língua sin dueño" (SEVERO, 2011, p. 27). É uma terceira língua, constituída de forma sensível, espontânea, íntima e fundamental. Os indivíduos falam em uma língua híbrida, em um espaço comum e, ao mesmo tempo, um espaço de retirada. Bhabha prefere chamar essa relação intercultural de "entrelugar", como observado no trecho seguinte:

Exploram uma realidade interpessoal: uma realidade social que aparece na imagem poética, como se estivesse entre parênteses - esteticamente distanciada, contida, além de historicamente enquadrada. É difícil exprimir o ritmo e a improvisação [...], mas é impossível não ver neles a cura da história, uma comunidade apaziguada [...]. (BHABHA, 2011, p. 92) 


\section{TEMPO E MEMÓRIA POÉTICA}

Na fronteira, é possível observar a relação intrincada de apego, identificações e conflitos culturais. Os sujeitos que compõem esse espaço ambivalente no território nacional buscam reconhecimento do valor como indivíduos pertencentes ao local em que são inseridos e, ao mesmo tempo, a ressignificação de uma cultura totalizante, em que se reforça a ideia de dualidade discursiva em constante consonância, que culmina na criação de um lugar inédito de fala. Através de um apanhado memorialístico e histórico, pretendem-se outros desdobramentos da realidade social para que sejam possíveis representações minoritárias nos cenários cultural e literário.

Em "Vintioito", é evidenciado o papel da memória como peça fundamental para que o leitor possa, por meio da conservação de informações e impressões passadas adquiridas pelo movimento subjetivo do eu poético, experienciar a fronteira.

\section{Vintioito}

fas mucho tempo

los visiño se ayudavan.

\section{Como la ves aqueya}

Que se prendío fuego la casa del Correa.

Todos ayudamos sacá las cosa pra la vereda

Mientras la Mama yorava i gritava

Se batendo nu peito.

Dispós todos ayudemo limpá

i cada um fue trasendo alguna coisa.

Asta nu bar du Carlito fiserum rifa [...]

(SEVERO, 2011, p. 48)

A poética de Fabián Severo se compromete a apresentar novos entendimentos a respeito de uma realidade fronteiriça, na qual a imaginação individual e coletiva se fundem em um movimento que transforma a experiência resgatada pelo tempo linear, que insiste em emplacar o poder soberano - legislador em um 
tempo alternativo, produzindo ruídos no território uruguaio. De acordo com Bhabha (2014), existem duas possibilidades de reconhecer e significar o povo pertencente à fronteira. A primeira, a partir do prisma histórico, em que as culturas populares se tornam objetos, explicitando o caráter pedagógico ao produzir uma narrativa notada pela repetição em seu presente enunciativo, no qual há um respaldo na tradição, ou seja, em um passado contínuo, "que representa uma eternidade produzida por autogeração" (BHABHA, 2014, p. 340). A segunda é a performática, interfere na soberania da ideia de totalização da nação ao introduzir as culturas populares em destaque e suas nuances, levando a outras construções temporais que se distanciam das marcações historicamente delineadas, oportunizando uma literariedade diferenciada dos padrões estipulados pelo capital literário. Através do portunhol, como terceiro espaço, o “entrelugar” enuncia diferentes relações com a temporalidade e visibiliza, portanto, outras possíveis temporalidades no mapa do tempo linear e vazio.

No poema "Trintídóis”, o sujeito poético exterioriza a relação "instituição educacional” versus "alteridade", na qual não se busca uma comunicação ou respeito mediante à diversidade social. O que ocorre é o processo de silenciamento, exclusão e violência em relação ao “outro' que não comunga com o sistema institucional uruguaio e suas políticas linguísticas que visam a língua oficial como língua de prestígio, sem levar em conta o universo plural fronteiriço que também está presente e participa na composição da nação.

\section{Trintídóis}

Yo no quiría ir mas em la escula

Purque la maestra Rita, de primer año

Cada ves que yo ablava

Pidía pra que yo repitiera i disía

Vieron el cantito en su voz, así no se debe hablar

I todos rían de mim

como eya pidía que yo repitiera

yo repitía i eyos volvían se ri [...]

(SEVERO, 2011, p. 54) 
Ao introduzir a individualidade na nação, dissolve-se a ideia de que o povo é uníssono. As ambivalências contidas na fronteira, "zonas de controle ou de renúncia, de recordação e de esquecimento, de força ou dependência, de exclusão ou de participação" (BHABHA, 2014, p. 242), provocam fissuras no território hegemônico, nos âmbitos da realidade, e abalam as estruturas idealizadoras de uma comunidade imaginada que costuma modular e repetir tradições, voltando- se a um tempo histórico que reduz e desapropria o povo de sua alteridade.

O sujeito poético do poema "Cuarenticuatro", mediante a tentativa de recuperar de maneira verossímil a realidade fronteiriça por meio da memória diretamente atrelada às experiências intimistas e de caráter coletivo, aprofunda o leitor em um tempo deslocado e obscuro, distante dos holofotes do tempo histórico e celetista. Nesse processo de imersão em um tempo desconhecido, ocorre o efeito reverso, que é evidenciar essa "outra" temporalidade estranha diante do tempo pedagógico, mas de suma relevância para comprender a complexidade da fronteira. Vejamos:

\section{Cuarenticuatro}

\section{El negro deu de Navidá}

la sía de Judas pra mi madre.

Los visinõdinfrente fiserum um Judas

i botarum ele sentado na sía.

De noite puserum bomba i prenderum fogo.

$\mathrm{Au}$ outro día, bien sedinõ

el Negro foi i trose la sía pras casa.

Limpó toda, lijó i deu uma boa mano de pintura

dispó clavó uma almuada veia

i la sía fico noviña.

Mi madre istava felis

agora tiña sía pra fase as costura.

Ela nunca avía tido Navidá

(SEVERO, 2011, p. 70) 
Em “Curentisete”, Fabián Severo poetiza o cotidiano em Artigas, o patrimônio de seus falantes. Ao escrever em sua língua de afeto translitera, livre de toda submissão imposta pelo sistema educacional uruguaio, adotando um tempo "outro", não forjado pela ótica do sujeito pertencente ao imaginário da nação uruguaia, evidenciado e contado pela história. Tem-se o sujeito subalterno fronteiriço originário de Artigas:

\section{Curentisete}

Yo conosí la Negra dispôs de grande.

Eya me contó sua istoria purque dis que quiría

que yo iscriviera pra no sisquesé.

Ela num sabe iscrevé.

Eya dis que as lembrança cumesan aus cinco año.

Antes no se lembra de nada.

La única foto que tein es de eya com dos año

i istá com la Iaia num gayinero

atirando maís pras gayina [...]

(SEVERO, 2011, p. 75)

Josefina Ludmer (2013) ilustra de forma significativa o resgate da memória na ressignificação da realidade. Segundo a autora: "Memória possui uma necessidade de uma dupla temporalidade, a fim de construir um presente sempre deslocado e duplicado" (LUDMER, 2013, p. 50). Ou seja, todo movimento de imaginação e captura de lembranças pode vir a produzir realidade e, ao mesmo tempo, não ter compromisso com os fatos, podendo não distinguir realidade de ficção. Ludmer (2014, p. 9) afirma ainda que "todos nós somos capazes de imaginar, todos somos criadores". Por meio da relação do indivíduo e sua subjetividade com o coletivo é que se organiza a memória. Não se pode separar o individual do social, visto que é por meio do compartilhamento de experiências que é possível recordar. 
É substancial compreender que a memória não está aferrada ao passado. Todavia, a decisão pela rememoração no presente para resgatar o passado já está em ruína, uma vez que se trata de outra temporalidade. Há de se observar a transformação da temporalidade, que produz dissonâncias no tempo, permitindo presenciar a ininterrupta "crise do tempo", abrindo possibilidades para reflexões a respeito da história, da formação identitária e da memória.

Para Benedict Anderson (2008, p. 278), todas as alterações significativas na consciência acarretam também "amnésias típicas". A partir desses lapsos da memória em questões pontuais da história, surge o recontar. Não se é capaz de lembrar a infância de forma fidedigna na fase adulta, devido ao espaçamento do tempo. Há alternativas de resgates por meio de documentos e fotografias, o que evidencia os cortes na memória. Por conta desse distanciamento, "surge o conceito de pessoa, de identidade [...] a qual, por não poder ser lembrada, precisa ser narrada” (ANDERSON, 2008, p. 278). Não se pode esquecer que é através dessas rupturas e vivencias contínuas que se esboça o indivíduo.

A memória pública constituída pela mescla da memória individual e coletiva está inserida na memória global. Tendo a América Latina como protagonista, essa sempre esteve atrelada a uma memória política, marcada por esquecimentos, em momentos escolhidos na história para serem apagados. Porém, sem sucesso, uma vez que o sujeito minoritário sobrevive e duplica a memória local e global, que coabitam o mesmo espaço e se acrescentam.

Ao contemplar Artigas como uma interseção circunscrita nessa realidade, verificam-se os movimentos de desterritorialização que cortam a fronteira, sendo uma resposta clara a impossibilidade de estabilidade dentro de qualquer território, pois sempre haverá movimentos dos corpos, principalmente levando em conta toda a memória histórica local. Com um olhar observador, Severo vai resgatando experiências de sua infância, relatos de seus vizinhos, histórias reais e imaginadas a fim de poetizar em tom autobiográfico o cotidiano da fronteira, dando voz ao sujeito poético e seu povo, por meio das recordações. Ao mesmo tempo, busca-se denunciar essa desatenção da sociedade, conhecida como "oficial”, em relação aos diversos sujeitos que compõem a fronteira, lugar de abandono social, político e econômico. "Artigas no tiene presidente", "Artigas e uma terra pirdida nu Norte qui noum sai nus mapa” (SEVERO, 2011, pp. 25-28). 
Neste ponto de nossa análise, Ludmer contribui com a discussão, quando comenta a relevância da Literatura como instrumento eficaz e desarticulador das imagens criadas pelas comunidades imaginadas para pensar a nação. Para a autora: "A literatura é um eco múltiplo, deformado e monstruoso de alguma coisa ouvida e escrita que se quer duplicar, aparecendo simultaneamente como ficcional e real" (LUDMER, 2014, p. 138). A participação da Literatura pode ser pensada e sentida nos ruídos que produz ao longo do tempo na desconstrução do que é nação, devido às ressignificações contínuas de uma sociedade multifacetada.

\section{CONSIDERAÇÕES FINAIS}

Entende-se que a obra de Fabián Severo, Noite nu Norte/ Noche en el norte - poesía de la frontera, acomete em sua essência o cenário multifacetado da fronteira Artigas. O autor propõe transliterar. O fazer da escrita toma um sentido totalmente diferente do esperado, à medida que a memória traz à tona a palavra. Ao mesmo tempo, nos apresenta a origem do povo artiguense, numa mescla de culturas, que configura sua alteridade. $\mathrm{O}$ autor cria uma escrita híbrida, o portunhol, firmando um pacto entre suas experiências vividas e as do coletivo, através do lirismo poético, no qual sua voz e a de outros se divorciam das objetividades das relações meramente sociais e transcendem o cotidiano, ao favorecer múltiplas identificações dos sujeitos.

A prática poética revela-se como uma poderosa ferramenta de luta contra os paradigmas impostos pelas nações do centro que comandam as noções e julgamentos do campo literário. Simultaneamente, rompe-se com a ideia do tempo atrelado ao regime histórico, no qual se submete Artigas ao esquecimento, e se reconstroem as experiências sociais, através de outras relações temporais e valores. Consequentemente, a fronteira é ressignificada.

\section{REFERÊNCIAS}

ABRANTES, Fernanda Arruda. A escrita em línguas híbridas e a superação da tradição do silêncio dos sujeitos transfronteiriços: uma comparação entre a escrita literária em portunhol e em spanglish. 2018. Tese (Doutorado em Letras: Estudos Literários) - Universidade Federal de Juiz de Fora, Juiz de Fora, 2018. 
ANDERSON, Benedict. Comunidades imaginadas: reflexões sobre a origem e a difusão do nacionalismo. Tradução Denise Bottman. 6. ed. São Paulo: Companhia das Letras, 2008.

BHABHA, Homi K. O entrelugar das culturas. In: COUTINHO, Eduardo (org.). 0 bazar global e o clube dos cavalheiros ingleses. Rio de Janeiro: Rocco, 2011.

. O local da cultura. Tradução Gláucia Renate Gonçalves, Eliana Lourenço de Lima Reis e Myriam Ávila. 2. ed. Belo Horizonte: Editora UFMG, 2014.

FOUCAULT, Michel. Microfísica do poder. Organização e Tradução Roberto Machado. 19. ed. São Paulo: Graal, 2004.

LANDER, Edgardo (org.). A colonialidade do saber: eurocentrismo e ciências sociais perspectivas latino-americanas. Colección Sur. Buenos Aires: Clasco, 2005.

LUDMER, Josefina. Aqui América Latina: uma especulação. Tradução Rômulo Monte Alto. Belo Horizonte: Editora UFMG, 2013.

SEVERO, Fabián. Noite nu Norte/ Noche en el norte - poesía de la frontera. Montevidéu: Rumbo Editorial, 2011.

SPIVAK, Gayatri Chakravorty. Pode o subalterno falar? Tradução Sandra Regina Goulart Almeida, Marcos Pereira Feitosa e André Pereira. Belo Horizonte: Editora UFMG, 2010.

TORRES, Sonia. Desestabilizando o "Discurso Competente": o discurso hegemônico e as culturas híbridas. Gragoatá, Revista do Instituto de Letras da UFF, ed. UFF, Niterói, v. 1, n. 1, pp. 179-189, 1996. 